\title{
TEMPORAL, SEASONAL, AND SOLAR CYCLE VARIATIONS OF THE TOPSIDE PROTON CONCENTRATION AT ARECIBO
}

\author{
C. A. Tepley* and R. B. Kerr** \\ *National Astronomy and Ionosphere Center, Arecibo Observatory, Arecibo, PR \\ 00613, U.S.A. \\ **Department of Atmospheric and Oceanic Science, 2455 Hayward, The \\ University of Michigan, Ann Arbor, MI 48109, U.S.A.
}

\begin{abstract}
An estimate of the topside proton concentration can be obtained by analyzing the incoherent scatter radar autocorrelation function from that region. Our observations at Arecibo, Puerto Rico indicate that the $\mathrm{H}^{+}$to $\mathrm{O}^{+}$composition transition height often occurs as 10 as $450 \mathrm{~km}$ during winter nights, near solar minimum. In the sumer, the nighttime transition height is only slightly higher, near $600 \mathrm{~km}$. This height is also affected by the level of magnetic activity. Naximum concentrations of $\mathrm{H}^{+}$occur near 04:00 LT, with a minimum about twelve hours later. The observations of topside $\mathrm{H}^{+}$were acquired during the past six years as part of the Regular World Day experiments, and from studies of the low latitude hydrogen geocorona. In particular, we will emphasize the results obtained during the solstice and equinox periods of the Thermospheric Mapping Study.
\end{abstract}

\section{INTRODOCTION}

During previous times of minimum solar activity, there have been a number of studies of the behavior of the base of the protonosphere at Arecibo (e.8. $/ 1,2,3,4,5,6,7 /)$. Using the incoherent scatter radar technique, those measurements were used to deternine the transition height at which the dominant ion changes from $\mathrm{O}^{+}$to $\mathrm{H}^{+}$. The shape of the measured backscattered spectrum is dependent upon the relative mixture of different ions, and upon the magnitudes of the electron and ion temperatures $/ 8,9,10 /$. For ions of considerably different masses, such $a \mathrm{H}^{+}$and $\mathrm{O}^{+}$, the spectrum has a distinct signature that is characteristic of a superposition of a "light" and " heavy" ion spectrum. As well as the measurement of ion composition and temperatures, areful ansiysis of the data can also reveal separate drift velocities for the contributing ions $/ 7 /$.

Regular ground-based measurements using incoherent scatter radars can provide a powerful continuous monitor of the seasonal and solar cycle patterns of the coupled ionized and neutral atmospheric system. Simul taneous observations of the upper atmosphere take place periodically at the six incoherent scatter radars and several optical facilities worldwide. These experiment are conducted on so-called "World Days", which occur almost every month. One such coordinated experiment is the Thermospheric Mapping Study (TMS). Three TMS campaigns took place during the solstice periods of June 1984 and January 1985 , and in equinox, September 1984. The basic goal of these investigations is to provide a date base from which the genersl morphological behavior of the ionosphere and the thermosphere can be studied globelly.

Measurement s of electron density, electron and ion temperatures, and $0^{+}$composition have been made at Arecibo since 1966. Additionsl observations of ion drifts began in 1971 , and have continued to the present time. With few data gaps, most of the results from all siz radars have been archived in the newly established NCAR Incoherent Scatter Radar Data Base located at Boulder, Colorado. In this report, however, we will only present results from half of solar cycle, starting near solar maximum in the winter of 1980-81, through to the 1985-86 winter near solar minimum. Our emphasis in this paper is on the proton structure of the topside ionosphere at Arecibo. The data obtained during the ThS campaigns will be discussed in detail.

\section{MRTROMENTATION}

The Arecibo incoherent scatter radar ( $18.35^{\circ} \mathrm{N}, 66.75^{\circ} \mathrm{w}$ ) has been described previously by Behnke and Harper /11/. Observations of temperatures, ion drifts, and composition are derived from matching the shape of the radar autocorrelation function to theory, using 
nonlinear least squares fitting technique. Measurements are made between 200 and $600 \mathrm{~km}$ altitude by transmitting a $300 \mu \mathrm{pulse}$ and oversampling the received signal with time delays that represent $23 \mathrm{~km}$ height intervals. Most of the data discussed in this note were collected using a single frequency operational mode for the transmitter. Since october 1985, we have adopted a multiple frequency transmitter pulse coding for most upper atmospheric experiments. The advantages of using such a code are discussed by Sulzer $/ 12 /$.

The antenna is pointed 150 from the zenith and the azimuth is continuously rotated through $360^{\circ}$ while the data are sampled. A complete azimuth cycle requires about 16 minutes, A first order harmonic series is $f$ it to the measurements of the line-of-sight velocity in order to estimate the vertical and horizontal velocity components. The velocity along the magnetic field line is also determined, and combined with the measured ${ }^{+}$density to estimate the proton $f 1 u x$.

\section{RESULTS AND DISCUSSION}

A direct result of the analysis of incoherent scatter radar spectra, obtained from altitudes above about $450 \mathrm{~km}$. is the ratio of the proton to electron concentration. Figure 1 shows the temporal and altitude variation of this ratio for a 28-hour period during January 1984. The illustrated error 1 imits represent $+/$ - one standard deviation of the mean value. The dashed line at a value of 0.5 indicates the $0^{+}$to $\mathrm{H}^{+}$transition, assuming that only these ions contribute to the total ion density. This example illustrates that the transition height moves dowmard gradually after sunset from about $586 \mathrm{~km}$ at $21: 30$ AST to $540 \mathrm{~km}$ at $02: 30 \mathrm{AST}$, but then rises more rapidly after local sunrise which occurs near 05:20 AST at $586 \mathrm{~km}$ altitude. Good measurement of $\left[\mathrm{H}^{+}\right]$can be obtained even for heights a $10 \mathrm{w}$ as $450 \mathrm{~km}$. However, in the rest of this report, we will present results obtained by averaging over the top four heights of Figure 1 , that is, from 516 to $586 \mathrm{~km}$, with a mean altitude of $551 \mathrm{~km}$. In Figure 2, we have plotted the solar cycle variation of $\left[\mathrm{H}^{+}\right] /$[Ne] for winter. The figure shows this ratio increasing as solar minimum aproaches, and reaching a maximum earlier in the evening after sumset.

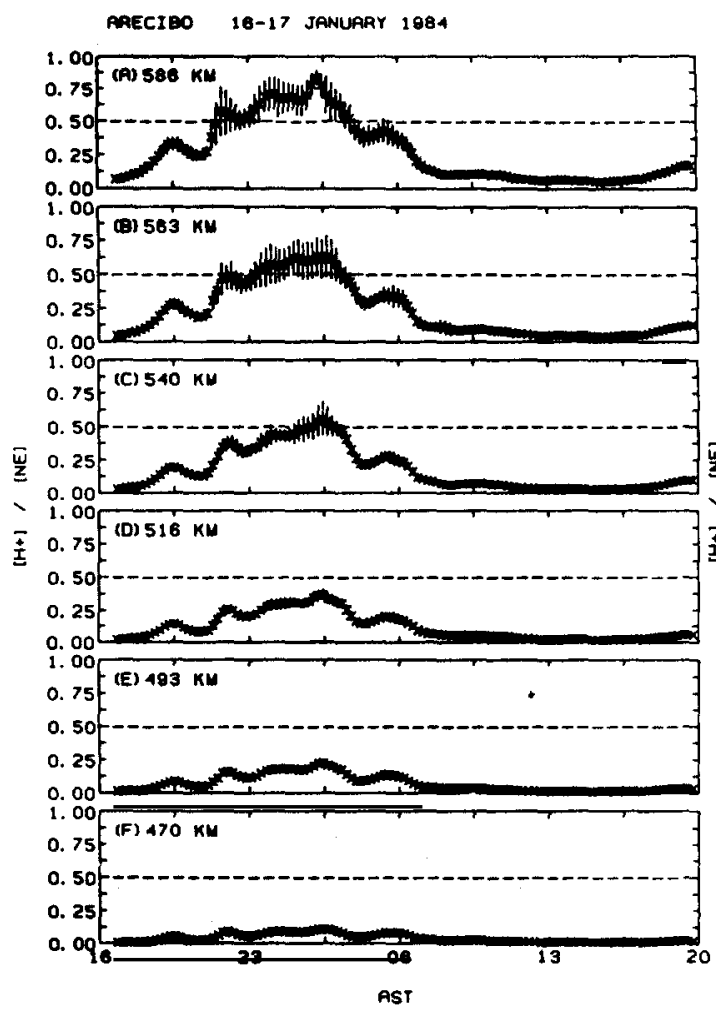

ARECIBO PROTON TO ELECTRON RATIO $1551 \mathrm{kM}$
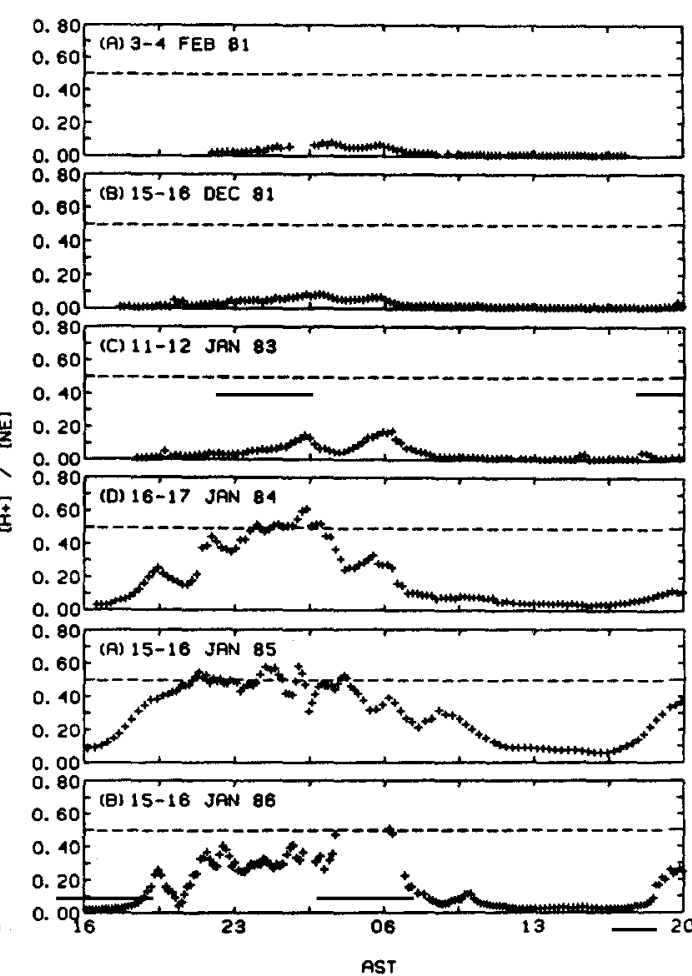

Fig. 1. The variation of the proton to electron concentration ratio with al titude for 16-17 January 1984. The dashed line represents the $\mathrm{O}^{+}$to $\mathrm{B}^{+}$transition height.

Fig. 2. The wintertime solar cycle variation of $\left[\mathrm{H}^{+}\right] /$[Ne] for an altitude average between 516 and $586 \mathrm{~km}$. 
Figures 3, 4, and 5 show the diurnal behavior of the electron and proton concentration of the topside ionosphere for Jume and September 1984, and January 1985, respectively. The magnetic dip angle for the $L=1.4$ flux tube at Arecibo is $50^{\circ}$. Positive fluxes are upward and equatorward. These $f$ igures show a significant difference between sumer and winter

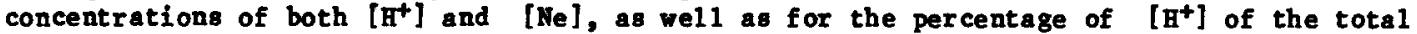
ion density, and $f$ or the magnitude of the flux. Generally, the component of [H+] flux along the field line is near zero during the day, and dormard at night as $\mathrm{H}^{+}$diffuses from the protonosphere to maintain the nighttime ionosphere through charge exchange with atconic oxygen $/ 6 /$.

On 19 September 1984, a large magnetic storm took place starting at about 10:00 UT (06:00 AST). Three-hour tabulations of the Kp index showed a jump from 2 to 6 during this time. The effect of this storm was observed immediately at Arecibo where the $H^{+}$flux turned positive (Figure 4d). Positive fluxes of this magnitude are rare at these latitudes and represent a southward $f 10$ of ionization toward Arecibo from higher L-shells. An unusul daytime enhancement in the [ $\left.\mathrm{H}^{+}\right]$concentration at $551 \mathrm{~km}$ was also observed, peaking at about 11:30 AST, 5.5 hour after the storm commencement, and then decaying away to more steady state levels. This was coincident with an enhancement in [Ne]. $0+H^{+}$charge exchange must have been responsible for the enhanced electron density since the ratio of

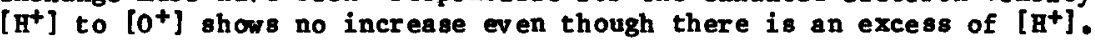

Kp values fluctuated between 4 and 6 for the rest of the day on 19 September 1984 , but no further enhancements in $\left[\mathrm{H}^{+}\right]$were observed. Some of the excess $\mathrm{H}^{+}$was probably consumed through the charge exchange mentioned previously. $\mathrm{H}^{+}$should be replenished at night through the inverse reaction of $\mathrm{H}+\mathrm{O}^{+}$. However, $\mathrm{H}+\mathrm{H}^{+}$charge exchange reactions also takes place leaving the resultant neutral hydrogen with enough excess energy to escape the exosphere $/ 13,14 /$. The depressed amounts of [H] for the two days following 19 September are consistent with a depleted flux tube, which is in the process of refiling after the st orm $/ 15 /$.

ARECIBO 25-28 JUNE 1984 (551 $\mathrm{kM}$

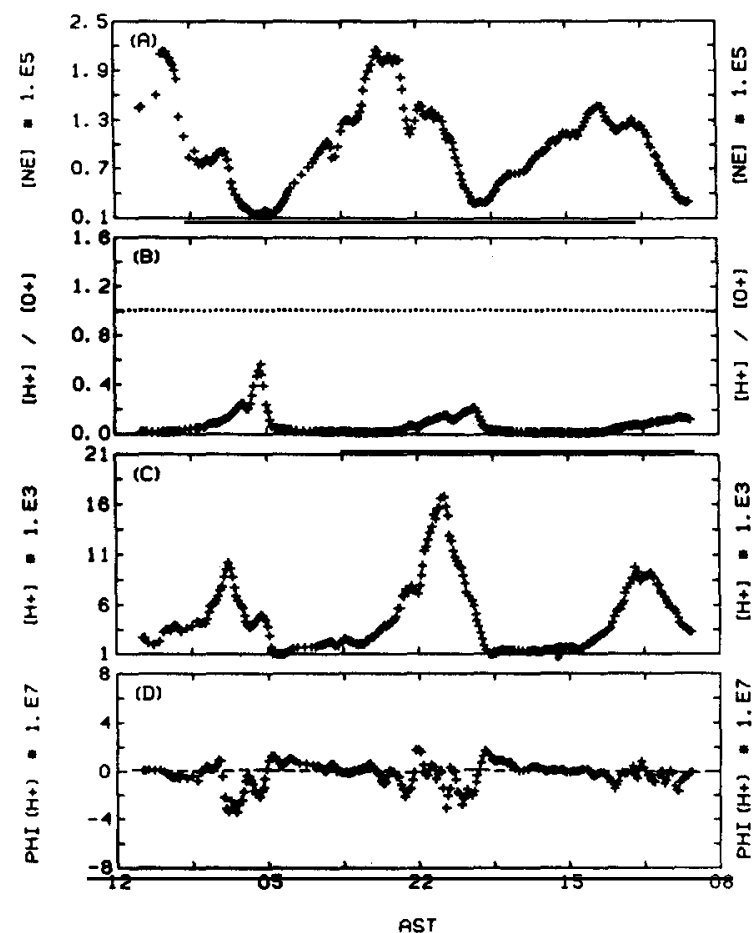

ARECIBO 18-21 SEPTEMBER 1984 (551 KM)

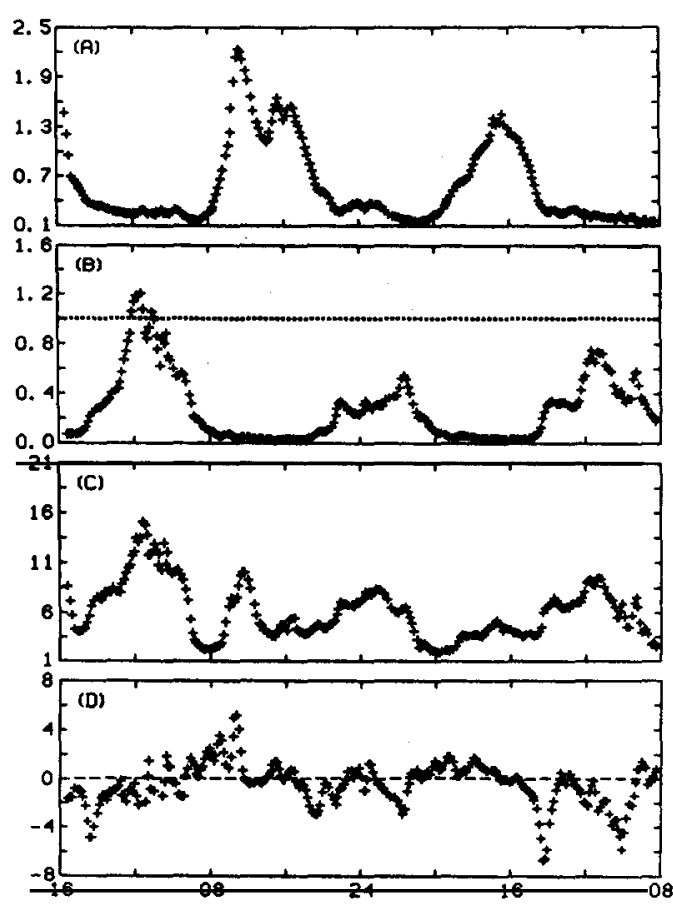

AST

Fig. 3. Diurnal variations of the electron and proton densities (cm-3), the ratio of $\left[\mathrm{H}^{+}\right]$to $\left[\mathrm{O}^{+}\right]$, and the field al igned proton flux $\left(\mathrm{cm}^{-2} \mathrm{~g}^{-1}\right)$ for $25-28 \mathrm{Jume} 1984$.

Fig. 4. Same as Figure 3, but for 18-21 September 1984. 


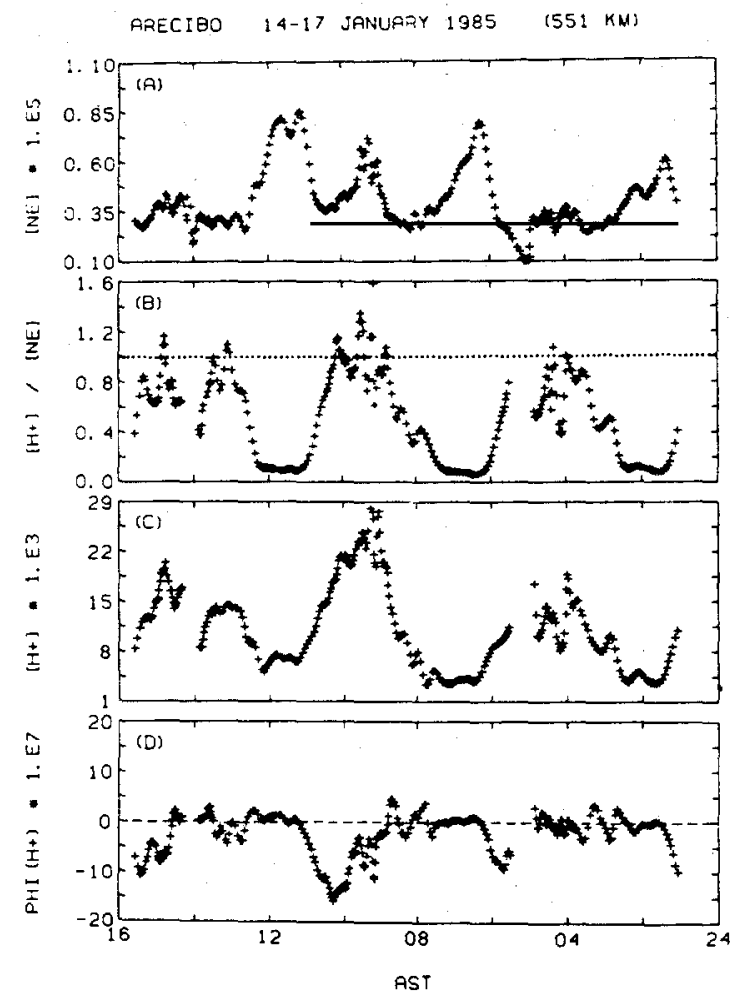

Fig. 5. Same as Figure 3, but for 14-17 January 1985.

We have shown that incoherent scatter radar measurement of the proton content of the topside ionosphere can be achieved routinely. Similar observations using other radars could assess the latitudina 1 and local time variations of $\left[\mathrm{H}^{+}\right]$and the proton flux.

\section{ACKNOWLEDGEMEYTS}

We thank R. Behnke and C. Gonzales for acquiring the data before 1983, M. Sulzer for his significant contributions to the data acquisition programs, and $R_{\text {. Burnside for many }}$ useful discussions about these results. The Arecibo observatory is operated by Cornell University under contract with the U.S. National Science Foundstion.

\section{REFER ETCES}

1. H. C. Car1son and W. B. Gordon, J. Geophys. Reg. 71, 5573 (1966)

2. J. B. Hagen and P. Y. Hsu, J. Geophys. Res. 79,4269 (1974)

3. M. C. Ho and D. R. Moor croft, Planet. Space Sci. 19, 1441 (1971b)

4. D. R. Moorcr of $t$, J. Geophy 8. Res. 74, 315 (1969)

5. D. E. Munninghoff and S. A. Bowhil1, J. Atmos. Terx. Phys. 43, 269 (1981)

6. J. F. Vickrey, W. E. Swartz, and D. T. Parley, J. Geophys. Reg. 84, 1310 (1979a)

7. J. F. Vickrey, W. E. Swartz, and D. T. Farley, J. Geophys. Res. 84, 7307 (1979b)

8. J. V. Evans, Proc. IEEE 57, 496 (1969)

9. M. C. Ho and $\frac{D}{D}$ R. Moorcr of $t$, Planet. Space Sci. 19, 1431 (1971a)

10. D. R. Moor cr of $t$, J. Geophys. Res. 69,955 (1964)

11 . R. A. Behnike and $\bar{R}$. M. Harper, I. Geophys. Res. 78, 8222 (1973)

12. M. P. Sulzer, Radio Sci. 21,737 (1986)

13. L. J. Waher and B. A. Tinsley, Planet. Space Sci, 26,855 (1978)

14. B. A. Tinsley, P1anet. Space sci. 26,847 (1978)

15. P. M. Banks, A. F. Ragy, and T. I. Axford, Plapet. Space Sci. 19, 1053 (1971) 